\title{
Telemedicine at sea and onshore: divergences and convergences
}

\author{
Matthieu J. Guitton ${ }^{1,2}$ \\ ${ }^{1}$ Faculty of Medicine, Laval University, Quebec City, QC, Canada \\ ${ }^{2}$ Institut Universitaire en Santé Mentale de Québec, Quebec City, QC, Canada
}

\begin{abstract}
Background: Telemedical Maritime Assistance Service (TMAS) is one of the fundamental components of medical assistance delivery at sea. However, while onshore telemedicine is undergoing a fast growth, these research and clinical investments unfortunately did not yet benefit for telemedicine at sea.

Divergences between telemedicine at sea and onshore: While telemedicine aims at providing distant health care, telemedicine at sea and onshore bear major differences, particularly for merchant vessels, and to a lesser extent for passenger vessels, which can be divided between structural differences, differences of practices, and policy differences.

Convergences between telemedicine at sea and onshore: Despite the existence of important divergences between telemedicine at sea and telemedicine onshore, these two major branches of distant health care delivery still converge in some respects.

Conclusions: Identifying the convergences between telemedicine at sea and telemedicine onshore might contribute to increase and optimise the transfer from research on onshore telemedicine to maritime telemedicine, and to overcome the relatively low amount of research performed on telemedicine at sea compared to its onshore counterpart.
\end{abstract}

(Int Marit Health 2015; 66, 1: 18-21)

Key words: telemedicine, TMAS, translational research, knowledge transfer

\section{INTRODUCTION}

Telemedical care or "telemedicine" gathers all the methods of distant health care delivery supported by remote communication technologies. In contrast to land telemedicine whose main developments mostly date from a few decades only, the use of telecommunication systems to provide distant health care in the maritime field can be traced back to the earliest days of radio-communication [1, 2]. By the middle of the $20^{\text {th }}$ century, maritime telemedicine was already standardised through the world by several countries and international organisations. While the standards of telemedical practices differ substantially between the various types of vessels (particularly between merchant ships and passenger ships in which medical professionals, either ship doctors or medically-qualified passengers, are present), Telemedical Maritime Assistance Service (TMAS) is nowadays one of the fundamental components of medical assistance delivery at sea, and is considered by the United Nations through the International Maritime Organisation as a part of the standardised rescue procedures [2].

In the last decade, onshore telemedicine has been considered as a potential avenue to answer the needs of the population for better health services at lesser costs. However, while onshore telemedicine is undergoing a fast growth, these research and clinical investments unfortunately did not yet benefit for telemedicine at sea. Considering that the conditions both for medical and telemedical care at sea are fundamentally different from what can be done onshore, the a priori transfer value of telemedicine experience gained onshore to the maritime field is low. However, and despite 
Table 1. Differences between telemedicine at sea and onshore

\begin{tabular}{|c|c|}
\hline At sea & Onshore \\
\hline \multicolumn{2}{|l|}{ Structural differences } \\
\hline Emergency response & Planned interventions \\
\hline Difficult data transfer due to limited bandwidth & Easy data transfer due to large bandwidth \\
\hline $\begin{array}{l}\text { Asymmetrical communication (Communication between lay people } \\
\text { [seafarers] and health professionals) }\end{array}$ & $\begin{array}{l}\text { Symmetrical communication (Communication between health } \\
\text { professionals) }\end{array}$ \\
\hline $\begin{array}{l}\text { Very long delay before supplementary medical assistance can be } \\
\text { achieved }\end{array}$ & $\begin{array}{l}\text { Limited delay before supplementary medical assistance can be } \\
\text { achieved }\end{array}$ \\
\hline \multicolumn{2}{|l|}{ Practice differences } \\
\hline Several referees & One referee \\
\hline $\begin{array}{l}\text { Health professionals have to work with incomplete health records } \\
\text { of the patients }\end{array}$ & $\begin{array}{l}\text { Health professionals work with complete health records } \\
\text { of the patients }\end{array}$ \\
\hline $\begin{array}{l}\text { Communication potentially not in the primary language of the } \\
\text { patients and/or the health professionals }\end{array}$ & $\begin{array}{l}\text { Communication usually in the primary language of the } \\
\text { patients and health professionals }\end{array}$ \\
\hline Multinational legal context & One single national legal context \\
\hline No use of pictures or video & Heavy use of video technology \\
\hline No complementary medical exams & Heavy use of complementary medical exams \\
\hline \multicolumn{2}{|l|}{ Policy differences } \\
\hline Old and stable & Relatively new and fast growing \\
\hline Target of very few research & Target of major research efforts \\
\hline
\end{tabular}

the existence of important divergences between telemedicine at sea and telemedicine onshore, these two major branches of distant health care delivery still converge in some respects. Identifying these convergences between telemedicine at sea and telemedicine onshore might make it possible to increase and optimise the transfer from research on onshore telemedicine to maritime telemedicine, and to overcome the relatively low amount of research performed on telemedicine at sea compared to its onshore counterpart.

\section{DIVERGENCES BETWEEN TELEMEDICINE AT SEA AND TELEMEDICINE ONSHORE}

While telemedicine, both at sea and onshore, aims at providing distant health care, these two forms of telemedicine still bear major differences. These differences can be roughly divided between structural differences, and differences of practices resulting from these primary structural differences (Table 1).

The first fundamental difference between telemedicine at sea and onshore is that telemedical health assistance is usually called for in emergency situations at sea, while onshore telemedicine interventions are planned in advance. It is here of importance to note that while emergencies are handled differently in passenger vessels and in merchant vessels due to the presence of medical professionals and often of better medical diagnostic equipment, any medical emergency requiring further investigations or expertise in a passenger vessel would ultimately necessitate a tele- medical intervention as well. The second major structural difference between the two forms of telemedicine is that the transfer of data at sea is often problematic, due to the fact that bandwidth can be extremely limited. A third structural difference between telemedicine at sea and onshore is that, while telemedical interventions onshore usually take place between equally educated health professionals, medical communications between a ship and the coast usually take place between seafarers who are not medical specialists and health professionals (again with the notable exception of passenger vessels), creating a major asymmetry in the communication [3]. Finally, the size of the maritime field (the oceans cover two-thirds of Earth's surface) makes the delay before supplementary medical assistance can be physically delivered to travelling ships potentially very long.

The very existence of this first series of structural differences leads to a set of secondary differences between telemedicine at sea and onshore: differences in the actual telemedical practice (Table 1). Due to the unplanned character of the vast majority of maritime telemedicine interventions, patients at sea do not have always the same medical referee. While onshore, the same medical team with the same health professionals will take care of a given patient, the situation is different at sea where patients might be taken care of by different health professionals, depending on the location of the ship and the availability of coastal radio stations. While most TMAS provide their service worldwide 
in order to allow seafarers to contact their national TMAS and thus avoiding both the issues of changing referees and health care delivery in a language which would not be the primary language of the patient - this is still constrained by satellite connection, which might be an issue in emergency situations. Related to this issue, a second problem lies in the fact that in the context of maritime telemedicine, health professionals have to work with incomplete patient health records. Third, telemedical care at sea takes obviously place in a multinational legal context, with all the related issues regarding legal obligations and responsibility [2]. While telemedicine on shore makes a heavy use of pictures and video technologies, this is quite limited at sea, due to the issues regarding the potential for data transfer. Combined with the fact that a boat cannot possibly offer the same facilities as ground centres in terms of medical equipment, the limited medical education of seafarers compromises the possibility to rely on complementary medical exams - which are in contrast central in onshore telemedical practice. Obviously, the situation is slightly better in passenger vessels, which usually have higher standard in medical equipment and capacities. Nonetheless, while passenger vessels might have an electrocardiogram (ECG) or photograph facilities, they are still unlikely to have complete biochemical analyses facilities comparable to what can be found onshore. Furthermore, the actual utilisation of medical equipment on board is often problematic. For instance, a large-scale study reported that, while ECG equipment was available in quite a lot of ships, actual recording was problematic in $23 \%$ of the cases, and transmission of the results was an issue in $17 \%$ of the cases, strongly questioning the reliability of this complementary exam in the maritime context [4].

Finally, a last - but not least - type of difference exists beside the structural differences and differences of practice, policy differences (Table 1). Policy differences reflect the way maritime telemedicine is perceived by governments and decision makers, and the degree of prioritising of maritime telemedicine among the different components of the public health system. In this view, telemedicine at sea is a form of telemedicine which has existed for a rather long time when compared to onshore telemedicine, and which is relatively stable in terms of patients. Unfortunately, telemedicine at sea does not appear as a major priority in terms of public health, and is not the target of massive research efforts. Obviously, these policy differences strongly impact the evaluation of current approaches, and the development of efficient and innovative solutions.

\section{CONVERGENCES BETWEEN TELEMEDICINE AT SEA AND TELEMEDICINE ONSHORE}

Despite all the differences and limitations, some of the knowledge gained via onshore experience can be trans- ferred to maritime settings. Specifically, some particular points of convergence can be identified between telemedicine onshore and at sea.

Considering onshore telemedicine as a single and monolithic entity would be a major mistake. The population covered by land-based telemedicine is obviously considerably larger and more diversified than the population of seafarers covered by maritime telemedicine. Therefore, onshore telemedicine applications are extremely varied. While the transfer value of onshore telemedicine to maritime telemedicine might appear low when onshore telemedicine is taken as a whole, things are different when considering specific populations and targeted applications. For instance, some of the defining conditions of maritime health care strongly echo the challenges posed by space medicine [5]. More interestingly, the issues that telemedicine faces when dealing with remote populations - for instance, the population of the northern parts of Canada - are almost similar with those faced by telemedicine at sea: limited bandwidth, impossibility to physically reach the population in a reasonable delay, communication between health professional and lay people, etc. [6, 7].

Some of the most recent directions of onshore telemedicine development may also bring more convergence with the needs and practices of maritime telemedicine. Indeed, while most onshore telemedicine applications so far have been designed to allow communication between health care professionals, this situation is quickly evolving. Due both to the drastic advances in information technologies and democratization of connected devices on the one hand, and to the growing needs for public health systems to provide more services with limited resources on the other hand, more and more telemedicine applications are designed to reach the patients directly. This represents a major paradigm shift in the way telemedicine is provided, as communications in this context occur more and more directly between the patients and health professionals through telemedicine applications - and not anymore solely between health professionals. With this heavy trend in contemporary telemedicine research and interventions, communications in onshore telemedical settings becomes more comparable to the situation observed on board. Hence, the potential transfer value of some of the new and future research on patient-targeted telemedicine interventions to telemedicine at sea is considerably higher than it used to be.

The possibility of adding other media to the conventional radio-consultation, particularly visual material such as pictures or real time videos, is another point of convergence between telemedicine onshore and at sea. Indeed, while the use of visual material has been limited so far in the context of maritime telemedicine, the emergence of new channels of communication such as satellite Internet access is drastically modifying the situation. Although limited research on 
this topic has prevented a wider use of visual materials in the context of telemedicine at sea, some benefits for using pictures and videos in order to provide additional information - either for the doctors ashore or for the patients on board - have already been demonstrated. About two decades ago, early studies in oil rigs already suggested the potential of visual material to improve the assessment of health-related situations, and in fine, enhance the reliability of the decision made by the health professional ashore [8]. Specifically, the value of the use of pictures in the context of maritime telemedicine has well been documented in the case of injuries or dermatological insults [9]. These conclusions could easily be extended to other pathologies, such as otological issues $[6,10,11]$. Furthermore, the use of video has been suggested as a possibility to assist seafarers having to perform some specific medical acts, such as replacing a dislocated joint or performing complex suturing [3]. As fax systems are already widely available on board [4], the implementation of picture transfer from ships to land-based medical centres could be easily generalised. However, more research will still be needed to evaluate in a systematic way the potential added benefits of the use of visual material in complement to standard radio-communication protocols in a maritime health context.

Finally, despite the mandatory medical training required by several seafaring nations, the level of medical education and training of seafarers has been identified as one of the weakest points of the maritime telemedical chain, and therefore an element which should be the target of more efforts in order to strengthen the efficiency of health care delivery at sea [3]. All the experience obtained with patient (tele)education and distant learning programs could easily be used to enhance this particular aspect, and thus optimise the success rate of maritime telemedical interventions.

\section{CONCLUSIONS}

As sea travels are steadily growing, so is the need to optimise reliable evidence-based telemedical strategies. Harmonisation of the onboard telemedical systems (both in terms of devices and software), and between these systems and the systems of ashore TMAS facilities is likely to increase the quality of telemedically transmitted data. In addition, TMAS should be considered not only in the context of medical emergencies, but also in the context of general medical health problems of seafarers - particularly for issues such as chronic health issues. In this view, the development of maritime telemedical applications based on what is done onshore could be extremely fruitful.

While the limited amount of research specifically performed on telemedicine at sea clearly hinders the development of innovative solutions, enhancements of existing maritime telemedical approaches can still arise from targeted comparisons with what is done onshore. In-depth understanding of the characteristics, strengths, and specificities of both forms of telemedicine might pave the way for successful developments in the maritime field, resulting in better security levels and health status for seafarers.

\section{REFERENCES}

1. Goethe WHG. Medical care on ships without a doctor. Radio medical advice. In: Goethe WHG, Watson EN, Jones DT eds. Handbook of nautical medicine. Springer, Berlin, 1984, pp. 53-65.

2. Ricci G, Pirillo I, Rinuncini C, Amenta F. Medical assistance at the sea: legal and medico-legal problems. Int Marit Health 2014; 65: 205-209. doi: 10.5603/IMH.2014.0039.

3. Horneland AM. Maritime telemedicine - where to go and what to do. Int Marit Health 2009; 60: 36-39.

4. Dehours $E$, Vallé $B$, Bounes $V$ et al. User satisfaction with maritime telemedicine. J Telemed Telecare 2012; 18: 189-192. doi: 10.1258/jtt.2012.110910.

5. Guitton MJ. Challenges in space medicine. Public Health Front 2012; 1: 73-77. doi: 10.5963/PHF0103003.

6. Kokesh J, Ferguson AS, Patricoski $\mathrm{C}$ et al. Digital images for postsurgical follow-up of tympanostomy tubes in remote Alaska. Otolaryngology Head Neck Surg 2008; 139: 87-93. doi: 10.1016/j. otohns.2008.04.008

7. Guitton MJ. Cyber Behaviors in Canada. In: Yan Z ed. Encyclopedia of cyber behavior. IGI Global, Hershey, 2012, pp. 1316-1327. doi: 10.4018/978-1-4666-0315-8.ch105.

8. Armstrong IJ, Haston WS, Maclean JR. Telepresence for decision support offshore. J Telemed Telecare 1996; 2: 176-177.

9. Lucas R, Boniface K, Hite M. Skin disorders at sea. Int Marit Health 2010; 61: 9-12.

10. Patricoski C, Kokesh J, Ferguson AS et al. A comparison of in-person examination and video otoscope imaging for tympanostomy tube follow-up. Telemed J E Health 2003; 9: 331-344. doi: 10.1089/153056203772744653.

11. Guitton MJ. Telemedicine in tinnitus: feasibility, advantages, limitations and perspectives. ISRN Otolaryngol 2013; 2013: 218265. doi: 10.1155/2013/218265. 